\title{
Los vecinos de Nasca: entierros de la tradición Huarato del valle de Acarí, Perú
}

Les voisins de Nasca: les coutumes d'enterrements à Huarato, vallée de Acarí, Pérou

The neighborgs of Nasca: Huarato burial practices from the

Acari valley, Peru

Lidio M. Valdez

\section{(2) OpenEdition}

\section{Journals}

Edición electrónica

URL: http://journals.openedition.org/bifea/4717

DOI: $10.4000 /$ bifea. 4717

ISSN: 2076-5827

\section{Editor}

Institut Français d'Études Andines

\section{Edición impresa}

Fecha de publicación: 1 abril 2006

Paginación: 1-20

ISSN: 0303-7495

\section{Referencia electrónica}

Lidio M. Valdez, « Los vecinos de Nasca: entierros de la tradición Huarato del valle de Acarí, Perú », Bulletin de l'Institut français d'études andines [En línea], 35 (1) | 2006, Publicado el 08 abril 2006, consultado el 02 diciembre 2020. URL : http://journals.openedition.org/bifea/4717 ; DOI : https:// doi.org/10.4000/bifea.4717

\section{(c) $(1) \odot$}

Les contenus du Bulletin de l'Institut français d'études andines sont mis à disposition selon les termes de la licence Creative Commons Attribution - Pas d'Utilisation Commerciale - Pas de Modification 4.0 International. 


\title{
Los vecinos de Nasca: entierros de la tradición Huarato del valle de Acarí, Perú*
}

\author{
Lidio M. Valdez**
}

\section{Resumen}

En este artículo se presenta uno de los resultados de los recientes trabajos de investigación efectuados en los tres sitios del Periodo Intermedio Temprano del valle de Acarí. Se trata de las formas de enterramiento y del respectivo tratamiento de los muertos practicado por la tradición local de Acarí. El resultado revela que habían por lo menos cuatro formas de enterramientos, una de las cuales parece haber estado reservado para los infantes y las otras formas utilizadas para cualquier individuo, incluyendo incluso a los infantes. Con una sola excepción, las estructuras mortuorias fueron construidas para cada individuo, donde los cuerpos fueron colocados envueltos en tejidos manteniendo una posición sentada, con las rodillas flexionadas hacia el pecho, los brazos cruzados por debajo de las extremidades inferiores, y las manos colocadas cerca de los genitales o de los pies. Muchas de las tumbas tenían un techo, mientras que sólo algunos individuos, sin diferencia de sexo y edad, poseían ofrendas. Comparado con las formas de enterramiento Nasca, los recientemente excavados en Acarí son del todo diferentes, ratificando de este modo que durante este periodo este valle fue habitado por una tradición local.

Palabras clave: Acarí, Nasca, tumbas, Periodo Intermedio Temprano, Costa Sur, Andes Centrales

\footnotetext{
Mientras una mayoría de especialistas que estudian Nasca ya aceptan que Nasca nunca llegó a establecer una organización estatal (Carmichael, 1995: 181; Proulx, 2001: 129; Schreiber, 1998: 262), algunos continúan manteniendo la vieja posición que ve a Nasca como una entidad organizada a un nivel identificable como Estado (para una discusión, ver Silverman \& Proulx, 2002: 238-239, 248). Ellos, incluyendo a Johny Isla, no sólo sostienen que Nasca fue un Estado, sino también aseguran que valles como Acarí fueron ocupados por Nasca. Dicha posición entra en desacuerdo con los planteamientos ofrecidos en este trabajo, por ejemplo, el mismo que en lugar de ofrecer evidencias Nasca provenientes de Acarí denota una ocupación distinta. En la opinión de Isla, mi metodología y por consiguiente mi interpretación son herradas. Es preciso anotar, sin embargo, que en la más reciente evaluación de la cultura Nasca, Silverman \& Proulx (2002: 2) ya no consideran al valle de Acarí como perteneciente al territorio Nasca. Acarí aparece sólo entre la zona de influencia Nasca (Silverman \& Proulx, 2002: 80). Por lo tanto, el autor deja a los lectores sacar sus propias conclusiones sin la necesidad de ser influenciados por interpretaciones como la ofrecida en este trabajo.

** L. M. Valdez, Department of Anthropology \& Indigenous Studies Program, University of Victoria, Canadá. E-mail: Ivaldez@uvic.ca
} 


\title{
Les voisins de Nasca: les coutumes d'enterrements à Huarato, vallée de Acarí, Pérou
}

\section{Résumé}

Cet article présente les résultats de recherches archéologiques récemment entreprises sur trois sites de la Période Intermédiaire Ancienne dans la vallée de Acarí, sur la côte du sud du Pérou. Les résultats indiquent qu'il y avait au moins quatre types d'inhumation différentes, dont un semble avoir été réservé aux nouveaux-nés tandis que les trois autres ont été utilisés pour n'importe quel membre de la société, y compris les nouveaux-nés. Sauf dans un cas, chaque structure mortuaire a été construite pour loger un seul individu. Les corps ont été emveloppés dans des textiles et placés en position assise, avec les genoux pliés contre la poitrine, les bras placés sous les jambes et les mains près des organes génitaux ou les pieds. Plusieurs tombes avaient un toit, et seulement quelques-unes, sans différence d'âge ou de sexe, étaient accompagnées d'offrandes. Les pratiques funéraires discutées dans cet article diffèrent de façon significatives des celles pratiquées par la culture Nasca, ce qui prouve qu'à cette époque la vallée fut occupée par une tradition locale.

Mots clés : Acari, Nasca, tombes, Période Intermédiaire Ancienne, Côte Sud, Andes Centrales

\section{The neighborgs of Nasca: Huarato burial practices from the Acari valley, Peru}

\begin{abstract}
In this paper I report results of the recent archaeological research carried out at three Early Intermediate Period sites in the Acari Valley, on the south coast of Peru. Current results indicate that there were at least four different burial types, one of which appears to have been mainly reserved for infants while the other three were used for any member of the society, including infants. With one exception, each mortuary structure was built to house a single individual. Bodies were wrapped in textiles and placed in a seated posture, with the knees flexed towards the chest, the arms placed under the lower limbs and the hands near the genitals or the feet. In addition, body orientation is consistently toward north. Many graves were provided with a roof, while only some received offerings. These differences had nothing to do with age or sex, however. The mortuary customs discussed in this paper differ significantly from Nasca burial practices; for instance, Nasca goods are not among burial offerings. Such notable variations testify that Nasca and Huarato were different cultural traditions.
\end{abstract}

Key Words: Acari, Nasca, tombs, Early Intermediate Period, South Coast, Central Andes

\section{INTRODUCCIÓN}

En su monumental trabajo titulado Urban Settlements in Ancient Peru, publicado hace más de cuatro décadas, Rowe (1963: 11) discutió en detalle el caso de la arqueología del valle de Acarí de la costa sur peruana (fig. 1) y distinguió una tradición local perteneciente a la fase 2 del Periodo Intermedio Temprano. Dicha tradición local, al decir de Rowe, habría sido sustituida por la cerámica Nasca de la fase 3 (Carmichael, 1992; Valdez, 2005a). Hasta hace poco, esta fue la 


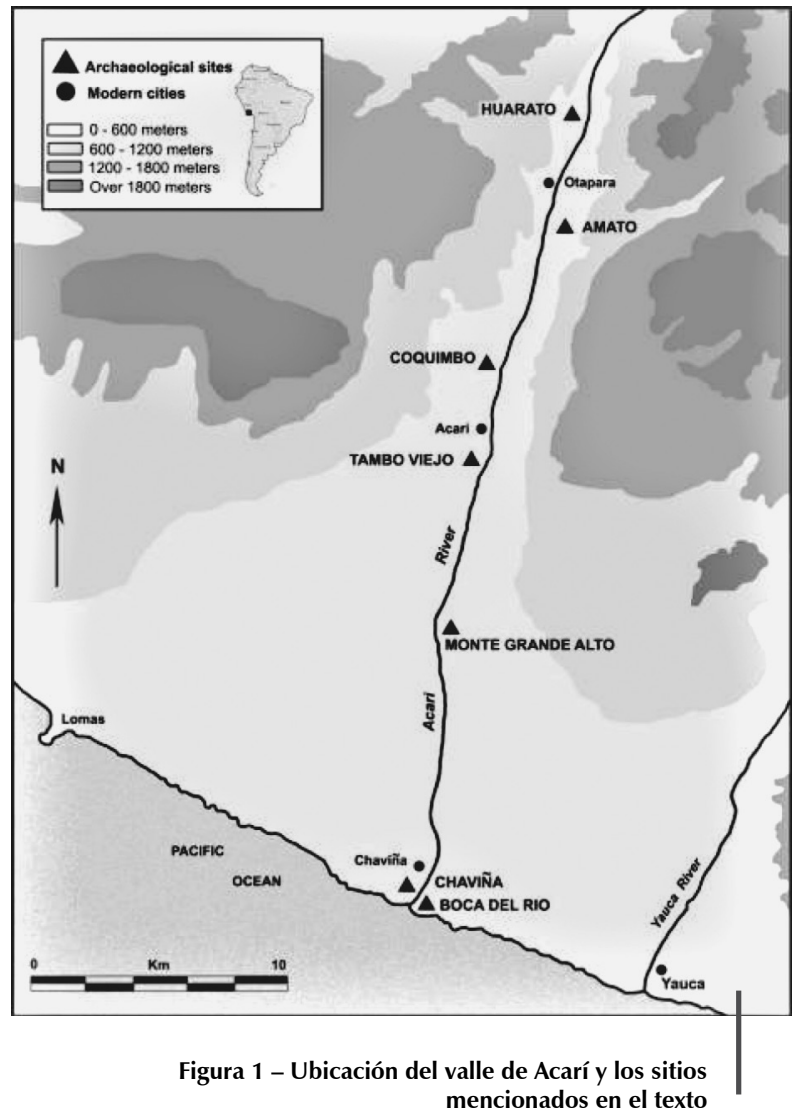

única referencia publicada con respecto a la tradición local de Acarí. Entretanto, la presencia de la cerámica Nasca temprano, que en la opinión de Rowe representaba una posible invasión Nasca, despertó un interés tal vez más allá de lo esperado, a tal extremo que sirvió como base principal para el desarrollo de todo un concepto que inició a percibir a la cultura Nasca como una organización no solo militarista, sino también expansiva (Lanning, 1967: 121; Proulx, 1968: 97; Massey, 1986: 338; Moseley, 1992: 186187; Silverman, 1988: 427).

Sin duda alguna, el estudio de la cultura Nasca ha atraído la atención de muchos investigadores y esto incluye al mismo Uhle (ver Rowe, 1954), a Kroeber \& Strong (1924) a Strong (1957), Menzel et al. (1964), Sawyer (1961) y a Silverman \& Proulx (2002), sólo para nombrar a algunos. La cerámica Nasca en particular, una de las más bellas de toda la América pre-hispánica (Carmichael, 1988), ha llamado la atención de muchos investigadores (ver Proulx, 1968; Carmichael, 1998; Vaughn \& Neff, 2000). Al mismo tiempo, y por coincidencia, el hallazgo de las así llamadas «cabezas trofeo» (Proulx, 1971; 2001) sirvieron como prueba del aparente carácter militarista y expansivo de la cultura Nasca, que se empezó a percibir como un Estado que conquistó a sus vecinos, incluyendo a los de Acarí. Esta reconstrucción, evaluada dentro del contexto del desarrollo de la arqueología americana en general, gana cierto sentido por cuanto este fue el periodo durante el cual muchos investigadores iniciaron a discutir fervorosamente el concepto de Estado (ver Carneiro, 1970; Service, 1962; Fried 1968; Flannery, 1972).

Esta breve introducción deja evidente que, en vez de determinar el carácter de la tradición local identificada por Rowe (1963), conocer más acerca de su origen, y evaluar el contexto en el cual la fina cerámica Nasca fue introducida, los especialistas dieron preferencia al estudio del supuesto carácter expansivo de la sociedad Nasca. Puesto que la arqueología del valle de Acarí fue inmersa en esta discusión, queda también manifiesto que el desarrollo local de Acarí fue desde un inicio analizado desde fuera y, en este caso, siempre con los ojos puestos en Nasca. De este modo, el prestigio de la cerámica Nasca y el aparente carácter militarista de Nasca opacaron del todo a la tradición local de Acarí a tal extremo que dicho desarrollo local no fue motivo de estudio alguno (Valdez, 1998; 2000a; 2005a). Mientras las discusiones siguieron su curso, los mismos investigadores interesados en el estudio de la «expansión» Nasca nunca llegaron a investigar sitio alguno del valle de Acarí; lejos de verificar empíricamente la supuesta conquista Nasca, los especialistas se conformaron con repetir las sugerencias de Rowe (1963).

Con el interés de evaluar la supuesta invasión Nasca y la dinámica del desarrollo cultural del valle de Acarí durante el periodo Intermedio Temprano, dentro del programa de investigaciones 
del «Proyecto Arqueológico Acarí», se ha optado por llevar adelante excavaciones arqueológicas en los sitios del referido periodo en el valle de Acarí (Valdez, 2005a; 2005b). Durante las fases iniciales del proyecto se ha llegado a excavar en dos sitios. Durante la temporada de 2004 las excavaciones se centraron en el sitio de Huarato y durante la temporada de 2005 en el sitio de Amato. Al mismo tiempo, trabajos de rescate fueron efectuados en los sitios de Monte Grande Alto y Tambo Viejo. Entre otros, dichos trabajos permitieron acumular información nueva con respecto a las formas mortuorias practicadas en este valle durante las fases tempranas del periodo Intermedio Temprano. Como se podrá notar en las líneas que siguen, el análisis de los patrones funerarios es de mucha importancia para comprender a cualquier sociedad, precisamente porque este tipo de institución es bastante conservadora dentro de toda sociedad. Esto quiere decir que las formas de enterramiento son en cierta medida únicas y como tales permiten distinguir una tradición de otra (Valdez, 2005b; 2005c). Por cuanto los patrones de enterramiento Nasca han sido motivo de buenos análisis (Carmichael, 1988; 1995), este estudio también permite comparar y contrastar los patrones de enterramientos de Acarí y Nasca.

Antes de presentar los datos con respecto a los patrones de enterramiento, considero oportuno dar una breve información sobre los sitios investigados, así como sobre los estudios previamente efectuados en cada uno de dichos sitios. Por consiguiente, los sitios en referencia son brevemente descritos, para luego abordar el caso de las formas mortuorias asociadas a cada uno de estos sitios.

\section{LOS SITIOS DEL PERIODO INTERMEDIO TEMPRANO DE ACARÍ}

A lo largo del valle formado por el río Acarí se encuentran distribuidos varios sitios arqueológicos (ver fig. 1) que, como característica principal, presentan muros perimétricos que, en varios casos, encierran por completo cada conjunto arqueológico (Riddell \& Valdez, 1988; Valdez, 1998; 2000a). Desde la cuenca alta del valle, la distribución de tales sitios es la siguiente: Huarato, Amato, Coquimbo, Tambo Viejo, Monte Grande Alto, Chaviña y Boca del Río. En las cercanías de Tambo Viejo al parecer se encuentra el sitio de Elsar inicialmente identificado por Rowe en 1959 y luego visitado en 1961 (Valdez, 2000a: 160). Dichos sitios pertenecen a las fases iniciales del periodo Intermedio Temprano. El caso de Chaviña es un poco diferente por cuanto fue durante las fases finales de dicho periodo que ganó mayor importancia (Valdez, 1994: 360; 1998: 89). Sin embargo, Chaviña parece haber sido inicialmente construido al mismo tiempo que Huarato y Amato.

El sitio de Huarato se encuentra en la parte superior del valle, en el margen derecho del río Acarí y en las inmediaciones del poblado de Huarato. Gran parte del sitio que daba hacia las inmediaciones del río ha sido completamente destruido y luego convertido en terrenos de cultivo (fig. 2). Como resultado, sólo queda una porción bastante pequeña de lo que parece haber sido un extenso asentamiento. Dicha porción presenta tres muros largos que encierran la periferia de los lados norte, oeste y sur. Es muy probable que todo el conjunto arqueológico fuera inicialmente rodeado por completo por un muro.

Lo que queda del sitio ha sido también el foco de intensos trabajos de saqueo que han alterado severamente el contexto arqueológico. En los años anteriores a 1939 Alfredo Carpio había visitado varios sitios del valle de Acarí, llegando incluso a excavar en Chaviña y Huarato. En su reporte presentado en Lima en 1939 en el marco del XXVII Congreso Internacional de Americanistas, Carpio (1942: 502) menciona que Huarato ya había sido visitado por los huaqueros. Posteriormente, Rowe, en compañía de D. Menzel, F. A. Riddell, C. Wallace y D. Wallace, también llegó a visitar el sitio. Rowe (1956) identificó a Huarato como un cementerio Nasca de las fases 2 y 3 . Desde entonces, Huarato ha sido continuamente mencionado en la literatura especializada como un sitio Nasca temprano establecido en el valle de Acarí. Sin embargo, a parte de los trabajos de Carpio (1942), Huarato no fue objeto de estudios sistemáticos.

Por su parte, Amato, ubicado a corta distancia de Huarato, es otro sitio perteneciente al periodo Intermedio Temprano. A comparación de los demás sitios, este es uno de los mejor conservados, 


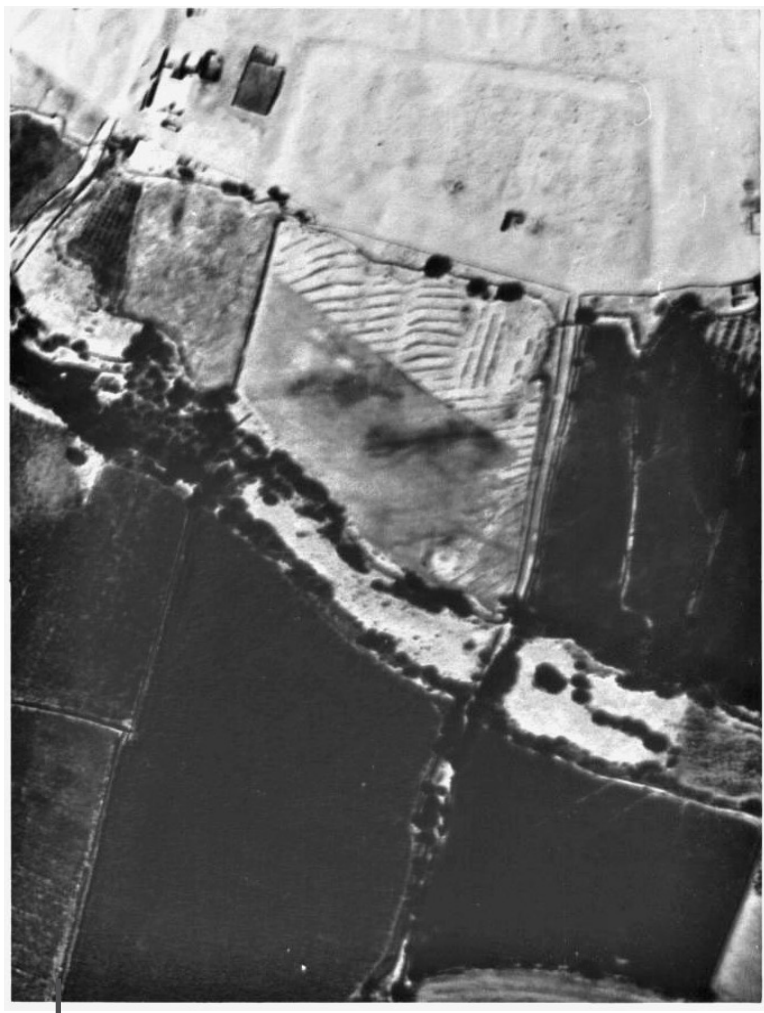

Figura 2 - Foto aérea del sitio de Huarato aunque la mano destructora de los huaqueros también ha dejado sus huellas. El sitio aparece rodeado por un muro perimétrico, en cuyo interior aparecen numerosas estructuras cuyas funciones por ahora se desconocen. Entre ellas resalta un recinto de forma cuadrada precisamente en la parte central del sitio, la misma que a su vez encierra otra estructura todavía más pequeña y de forma rectangular. Las excavaciones durante la temporada 2005 fueron efectuadas al interior de estas dos estructuras.

Por su parte, el sitio de Tambo Viejo, que se encuentra ubicado en la parte media del valle de Acarí, también había sido visitado por Carpio (1942). Sin embargo, los primeros estudios arqueológicos efectuados en Tambo Viejo están asociados con las investigaciones iniciadas allí por Dorothy Menzel y Francis A. Riddell en 1954 (Menzel \& Riddell, 1986; Valdez, 1998: 42). La visita inicial de Rowe a Tambo Viejo tomó lugar también en 1954 (Valdez, 1998: 43) y fue en base a la información obtenida durante dicha visita y aquella recuperada por Menzel y Riddell en 1954 que Rowe (1956: 137) sostuvo que la ocupación más temprana de Tambo Viejo estaba asociada con la cerámica Nasca 2 y 3 . En su posterior publicación,

Rowe (1963: 11) describió Tambo Viejo como un sitio rodeado por un muro de fortificación. En efecto, existe un muro grande al lado oeste del sitio, pero desafortunadamente gran parte del mismo ha sido destruido.

Por cuanto Tambo Viejo es un sitio con una larga ocupación prehispánica (Kent \& Kowta, 1994; Valdez, 1996), el sector que pertenece al periodo Intermedio Temprano no fue motivo de investigaciones arqueológicas hasta 1986 cuando los integrantes del California Institute for Peruvian Studies, dirigido por F. A. Riddell, efectuaron las primeras excavaciones. Dichos trabajos continuaron en 1987 y no obstante que permitieron el hallazgo de algunas muestras de cerámica Nasca temprano (Valdez, 1998), dichas intervenciones no dejaron de ser limitadas.

Por último, el sitio de Monte Grande Alto ha sido recién identificado en 1986 (Riddell \& Valdez, 1988). Al igual que los 3 sitios anteriores, Monte Grande Alto también presenta dos muros grandes que encierran por completo el conjunto arqueológico. Además, y a diferencia de los sitios anteriores que se encuentran en espacios abiertos, este último se encuentra en la cima alta de una planicie, desde donde hay una fuerte caída casi perpendicular hacia el río Acarí. En el momento en que el sitio fue ubicado en 1986 había claras evidencias de la intervención clandestina de los huaqueros, pero fue entre 1990 y 1996 cuando dicha actividad fue intensificada, alterando considerablemente al sitio arqueológico. Como resultado, durante mi visita en octubre de 1996 pude constatar no sólo una cantidad considerable de fragmentos de cerámica, sino también abundantes huesos humanos abandonados en la superficie (Valdez, 1998). Desafortunadamente, trabajos de excavación sistemáticos aún no se han efectuado en este sitio. 
De esta breve referencia, queda obvio que los sitios del periodo Intermedio Temprano del valle de Acarí no han recibido la atención necesaria de los especialistas. Por lo tanto, con las recientes excavaciones realizadas en Huarato (Valdez, 2005a; 2005b) y Amato (Valdez, 2005c) se inaugura toda una nueva etapa del estudio y análisis sistemático de los sitios Acarí. Con esta breve referencia, ahora paso a presentar las evidencias relacionadas a las formas de enterramiento encontradas en los sitios arriba mencionados. Luego, dicha información se compara y contrasta con la información que se conoce para los patrones de enterramiento Nasca (Carmichael, 1988; 1995; Orefici \& Drusini, 2003), para de este modo verificar las posibles diferencias y semejanzas entre las formas de enterramiento Nasca y Huarato.

\section{LAS FORMAS DE ENTERRAMIENTO DE LA TRADICION HUARATO}

Los recientes trabajos de rescate efectuados en los sitios de Monte Grande Alto y Tambo Viejo, así como las excavaciones realizadas en los sitios de Huarato y Amato permitieron el descubrimiento de varios entierros. Dichos hallazgos son los primeros para todos estos sitios y, como tales, proveen información no sólo nueva, sino también importante para empezar a discutir el caso de la ocupación del periodo Intermedio Temprano de este valle. Esta información no deja de ser bastante inicial y la muestra sigue siendo pequeña; sin embargo, para poder establecer una base para futuros análisis, es indispensable ordenar la información disponible y hacerla accesible a otros investigadores. En la medida que los trabajos continúen es posible que nuevas formas de enterramiento sean eventualmente descubiertas; cuando eso ocurre, planteamientos anteriores irán siendo verificados y de ser posible modificados. En consecuencia, mi intención es clasificar las varias formas de enterramiento observadas en los cuatro sitios aquí mencionados y, luego, explicar aunque de manera tentativa el significado de las variaciones observadas.

Teniendo en cuenta las variaciones en cuanto a la construcción de las tumbas se refiere, se puede distinguir hasta cuatro formas funerarias asociadas a los sitios aquí investigados. Este es un aspecto de mucho interés por cuanto las distintas formas representan diversos grados de energía invertida en la construcción de tales lugares de enterramiento. Como datos complementarios, pero útiles para hacer una comparación con Nasca, en esta discusión también se tiene en cuenta el tratamiento, orientación y posición de los entierros. A continuación, cada una de estas formas es descrita.

\section{1. Entierros en hoyos simples}

La primera forma de enterramiento definido para los sitios del periodo Intermedio Temprano del valle de Acarí consiste de un simple hoyo excavado en el suelo. Aunque hay varios entierros - desafortunadamente saqueados - que parecen pertenecer a este primer grupo, a la fecha sólo dos tumbas han sido excavadas. El primer entierro (T5 - MGA) fue recuperado durante la temporada de 2004 en el sitio de Monte Grande Alto (fig. 3). Para esto, un hoyo con una profundidad de 0,80 m y un diámetro promedio de 0,90 m había sido excavado en el suelo. Allí se depositaron los restos de un individuo de sexo femenino cuya edad oscila entre los 25 y 35 años. Estaba en posición sentada, con las rodillas flexionadas hacia el pecho, los brazos ligeramente cruzados por debajo de las extremidades inferiores y las manos próximas a los genitales. El cuerpo había sido depositado manteniendo una orientación hacia el norte; previamente, este había sido envuelto en un tejido (manto) llano y luego amarrado con una soguilla a la altura del abdomen, probablemente para sujetar el tejido. Finalmente, el entierro había sido cubierto con arena limpia. El entierro no tenía ofrenda alguna.

El segundo entierro perteneciente a esta forma ha sido recientemente excavado en el sitio de Amato (T5-Amato). En este caso, un hoyo había sido excavado en una formación de arena suelta, lo que no permitió definir el diámetro y la forma de la abertura. Ahí habían sido depositado los 
restos de otro individuo adulto de sexo masculino cuya edad oscila alrededor de los 60 años. Al igual que en el entierro anterior, el cuerpo estaba en una posición sentada, con las rodillas flexionadas hacia el pecho, los brazos en los costados y las manos cruzadas a la altura del distal de la tibia y del peroné. El cuerpo también mantenía una orientación hacia el norte; previamente había sido cubierto, incluyendo el rostro, por un tejido (manto) llano y luego sujetado a la altura del abdomen con una soguilla. En contraste con el primer entierro, a la altura de los pies del individuo, se ubicó un mate cubierto con un fragmento de cerámica. El mate estaba vacío; sin embargo, al lado derecho del individuo se había depositado gran cantidad de frutos de maní. Del mismo modo, y siempre al lado derecho del individuo, se hallaron un total de 5 camélidos jóvenes, sacrificados. A la espalda del individuo también habían numerosas cuentas de Spondylus, así como piezas de Spondylus trabajadas.

Parece tratarse de un personaje de particular importancia no sólo por su edad bastante avanzada, sino por el número y variedad de ofrendas depositadas. Efectivamente, este llevaba un collar hecho de cientos de huesos de ala (radio-cúbito) de alguna ave pequeña, complementada por pequeñas cuentas de conchas. Finalmente, a la altura de la cara del individuo se había depositado el cuerpo de otro individuo adulto, de sexo masculino cuya edad oscila entre los 35 y 49 años. Dicho individuo estaba colocado sobre su estomago y con los brazos colocados a los lados. Lo resaltante de este individuo depositado a modo de ofrenda es que fue decapitado. Este hallazgo será discutido en mayor detalle en otro trabajo; por ahora es suficiente mencionar que en las inmediaciones del individuo adulto había más de 40 individuos, todos decapitados, y que incluye una población conformada por individuos de ambos sexos y de todas las edades (Valdez et al., 2006). Una muestra de carbón recuperada cerca a la ofrenda de mate arrojó un fechado de $20 \mathrm{~d}$. C.

\section{2. Entierros en urnas}

La segunda forma de enterramiento definido para los sitios del periodo Intermedio Temprano del valle de Acarí es bastante similar a la primera. Esta consiste de un hoyo también excavado directamente en el suelo. El diámetro del hoyo oscila entre 0,90 y $0,70 \mathrm{~m}$ y la profundidad es aproximadamente de $0,80 \mathrm{~m}$. El hoyo tiene una forma ligeramente globular. Allí se depositaron los restos de un individuo, envuelto en un tejido (manto) llano, pero no se pudo notar de ninguna manera la presencia de una soguilla alrededor del torso. Una vez depositado el cadáver en el hoyo, y a diferencia de la forma anterior, el cuerpo había sido cubierto con una vasija (fig. 4). Para esto, la base de la vasija había sido previamente rota y luego colocada en posición vertical. Cubriendo la abertura de la vasija había una laja o —en el caso de las tumbas de Monte Grande Alto- con un pedazo de caliche, depositado a modo de cubierta. Finalmente, la vasija fue completamente cubierta con abundante tierra o arena.

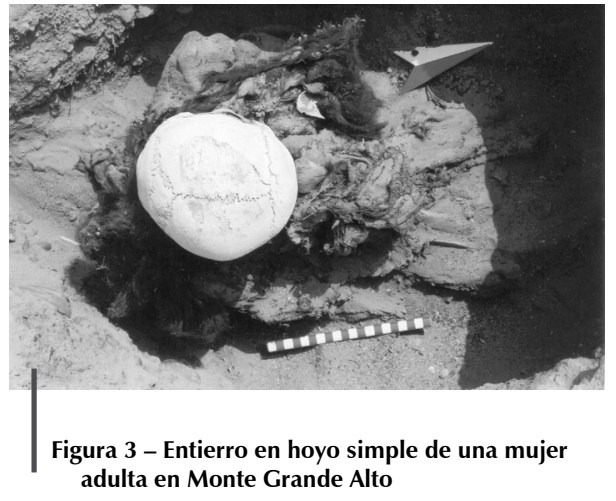

adulta en Monte Grande Alto

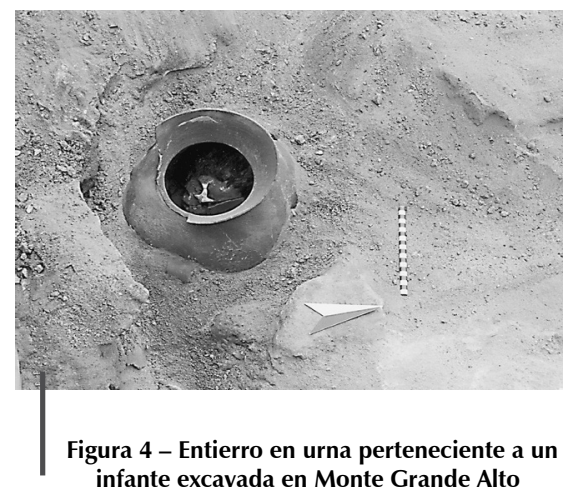

infante excavada en Monte Grande Alto 
En Monte Grande Alto se llegó a limpiar un total de cinco entierros de esta forma, de los cuales cuatro pertenecen a infantes/recién nacidos, mientras el quinto es un joven (fig. 4). Para los primeros no fue posible determinar la posición de los cuerpos, aunque sí para el individuo juvenil. Este mantenía la misma posición que los individuos adultos de la forma anterior. Entre todos estos hallazgos, un infante/recién nacido tenía como ofrenda una pequeña cantimplora no decorada. En 1996 observé un entierro similar en Tambo Viejo conteniendo los restos de un infante. En 1987 otro entierro similar fue excavado en el mismo sitio y los restos allí recuperados también pertenecían a un infante (Valdez, 1998: 146-147). Durante la temporada de 2004, un entierro (T7-Huarato) de este grupo fue excavado en Huarato; también contenía los restos de un infante (Valdez, 2005b: 53). Las recientes excavaciones efectuadas en Amato permitieron la ubicación de 3 entierros adicionales en urnas que también contenían los restos de infantes/ recién nacidos (T1, T2 y T4). Una de estas (T4-Amato), excavada en la parte central del recinto central del sitio, poseía como ofrenda un cuy y un mate. Los otros dos (T1 y T2 - Amato) fueron hallados en la afueras del muro Este del recinto rectangular, ambos colocados a una distancia aproximada de 1 metro uno del otro. Contenían infantes que tenían entre 1 y 3 años de edad.

Aunque esta asociación con infantes y recién nacidos parece sugerir que esta forma fue reservada para un sector particular de la población, las excavaciones en Amato permitieron exponer un entierro (T3-Amato) en urna pero que contenía los restos de un individuo adulto de sexo femenino, cuya edad oscila entre los 20 y 34 años. Una muestra de carbón recuperada de este contexto arrojó un fechado de 245 d. C. La posición, orientación y tratamiento del cuerpo son idénticos a los dos entierros del primer grupo, aunque en este caso no se encontró la soguilla alrededor del torso sujetando el manto en el que fue envuelto. La vasija en referencia, con la base rota, había sido colocada sobre la cabeza (para cubrir el cráneo), mientras que el resto del cuerpo descansaba directamente sobre una formación de arena. La abertura de la vasija estaba sellada con una laja. Sobre la vasija y el cuerpo se depositó abundante arena. No había ofrenda alguna asociada a la tumba.

\section{3. Entierros en hoyos con techo}

Las excavaciones realizadas en Huarato también permitieron exponer seis entierros diferentes a las dos formas anteriores. Estas consisten de hoyos cuya profundidad varía dependiendo de la edad del individuo enterrado. $\mathrm{Si}$ los individuos depositados son infantes, el hoyo es menos profundo $(0,60 \mathrm{~m})$, mientras que si el individuo depositado fue un adulto, la profunda supera fácilmente $1 \mathrm{~m}$. El hoyo tiende a ser ligeramente de forma cilíndrica, aunque en otros casos es poco globular, siendo la parte media ligeramente más ancha que la base y la abertura (Valdez, 2005b: 50). En algunos casos, la dimensión de la abertura fue intencionalmente reducida colocándose varias piedras unidas con argamasa. Las paredes del hoyo nunca fueron modificadas, y fue ahí donde los cuerpos fueron colocados manteniendo la misma posición que los individuos de las formas previamente referidas; es decir en una posición sentada (dos fueron hallados ligeramente inclinados a sus lados), con las rodillas flexionadas hacia el pecho, los brazos colocados por debajo de las extremidades inferiores y las manos cerca a los genitales o los pies (fig. 5). Los cuerpos siempre mantienen una orientación hacia el norte, y antes de ser depositados fueron envueltos en tejidos (mantos)

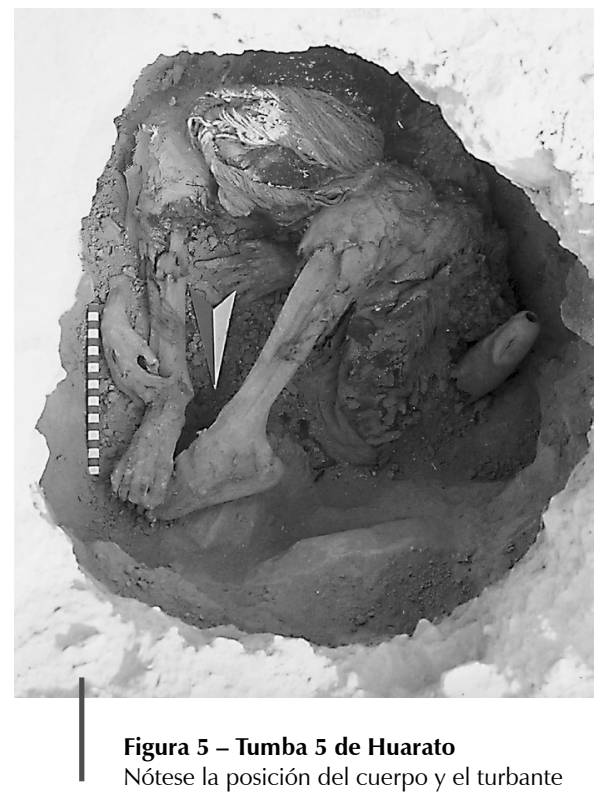

Nótese la posición del cuerpo y el turbante 
Ilanos. En un caso se pudo observar que el cuerpo había sido sujetado con una soguilla a la altura del torso. Esta vez, se trata de un adulto de sexo masculino.

Una vez que los cuerpos fueron colocados al interior del hoyo, este fue cubierto con un techo construido ya sea en base de lajas unidas con argamasa, ya sea de cañas (fig. 6). Dicho techo evitó la caída de la tierra al interior de la tumba. Luego, el techo fue sellado con una capa gruesa de arcilla, sobre la cual se halló, en dos casos (T2 y T5 - Huarato), ceniza y tierra quemada, sugiriendo que hubo fuego. Una vez consumido el fuego, otro sello de arcilla fue depositado. Excepto en un caso (T1-Huarato), sobre dicha cubierta final se colocó un pequeño canto rodado en posición vertical como señal de la tumba (fig. 7).

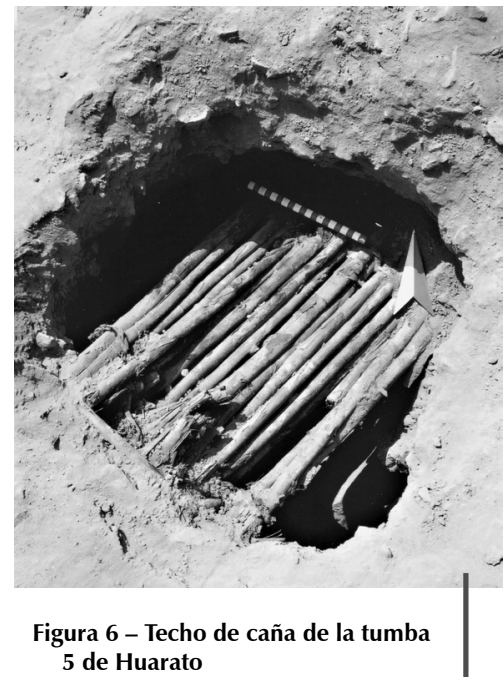

\section{4. Entierro múltiple}

Mientras la forma previamente descrita es de mejor elaboración que las anteriores, especialmente si se considera la forma comolostechosfueron preparados y la señal de tumba colocada precisamente en la parte superior de las tumbas (Valdez, 2005a; 2005c), una estructura funeraria que denota todavía una mejor elaboración fue recientemente excavada en Tambo Viejo. Dicha estructura, desafortunadamente, había sido saqueada en parte, y fue precisamente dicha intervención clandestina que permitió que la estructura sea posteriormente excavada. Cuando se llegó a observar la estructura por primera vez, al lado este había un hoyo lo suficientemente grande donde había una acumulación de escombros

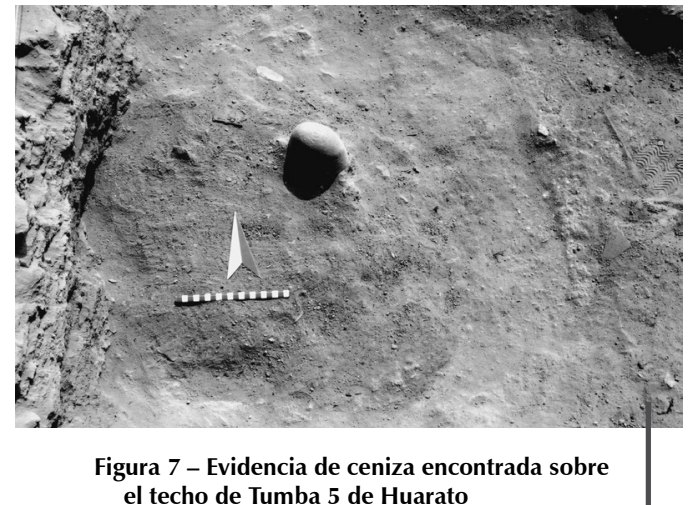

el techo de Tumba 5 de Huarato

1 Las ofrendas consisten en raíces de yuca, y no de camote como se menciona por error en un reporte inicial (Valdez, 2005b: 53). 
y algunos huesos humanos. Al mismo tiempo, al lado noroeste de dicho hoyo se notó una pequeña pared hecha de barro que en parte sostenía un techo de caña brava. Por debajo del techo se pudo observar de inmediato los restos de un individuo aún manteniendo una posición sentada y una orientación hacia el norte. Entre tanto, sobre el techo en mención, había varias piedras planas, unidas con barro, colocadas para sellar el techo de cañas y la tumba.

Con la finalidad de recuperar los restos óseos que estaban debajo del techo se procedió con la limpieza de esta parte de la estructura y eventualmente de toda la estructura (fig. 8). Durante este procedimiento se constató, primero, que la estructura tenía una pared construida de cantos rodados y una forma ligeramente ovoide. Luego se observó que la estructura había sido dividida en dos partes, mediante la construcción de un pequeño muro de barro que va de norte a sur. En el lado que da al este se habían depositado los restos de un adulto de sexo masculino, pero que desafortunadamente ya había sido saqueado por completo. Sobre una base empedrada y pegada a la pared del lado sur, sólo se pudo encontrar un cráneo que presenta un tipo de deformación en cierta medida única (fig. 9). Esta es de tipo fronto-occipital, donde el hueso frontal fue del todo aplanado. La correspondiente mandíbula fue hallada fragmentada en dos partes fuera de la estructura. Esto sugiere que la profanación de la estructura sucedió no hace mucho tiempo atrás. Otros huesos de este individuo no fueron hallados.
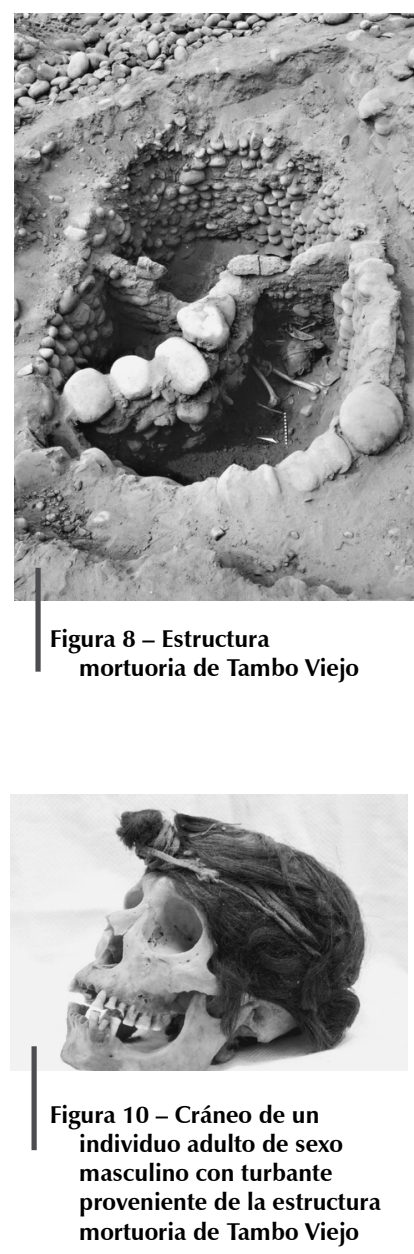

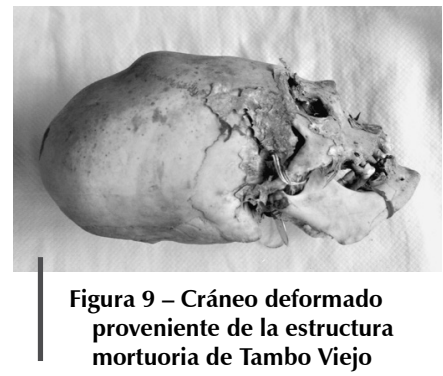

Al mismo tiempo, se procedió a limpiar el lado noroeste de la estructura donde, como se señaló, todavía estaban los restos de otro individuo manteniendo una posición sentada y con las rodillas flexionadas hacia el pecho. Una vez expuesto lo que quedaba del techo de cañas, se procedió a limpiar al interior de esta estructura para poder registrar y recuperar los restos óseos. Durante este procedimiento se constató, al lado sur, de la presencia de un muro hecho de cantos rodados que sub-dividía el lado oeste de la estructura. La espalda del individuo estaba apoyada a dicho muro y mantenía una orientación hacia el norte. Los restos pertenecen a un adulto de sexo femenino cuya edad oscila entre los 35 y 49 años. El único objeto hallado en asociación al entierro (ofrenda) fue la pata de un camélido.

Finalmente la limpieza del lado suroeste de la estructura permitió el hallazgo de un tercer individuo. Este viene a ser un adulto de sexo masculino que lleva un turbante negro (fig. 10) y cuya edad oscila entre los 35 y 49 años. Muchos de sus huesos ya no mantenían su posesión anatómica, sino estaban acumuladas en el extremo sureste de esta división. Se notó, además, que el muro de cantos rodados ubicado a su lado norte había sido levantado sobre los huesos tibia y fíbula de este último individuo, sugiriendo que el individuo 
de sexo femenino previamente mencionado fue añadido con posterioridad. Para su efecto, el lado oeste de la estructura tuvo que ser sub-dividido, proceso durante el cual los restos del individuo adulto de sexo masculino fueron arrimados hacia un lado.

La importancia de esta forma de enterramiento reside en que este es el primer caso donde se observa una estructura relativamente amplia cuya construcción requirió mayor esfuerzo. Al mismo tiempo, el aspecto tal vez de mayor significado es el hecho que en esta estructura se habían depositado los restos de hasta 3 individuos adultos: dos de sexo masculino y una de sexo femenino. En el relleno que cubría al segundo individuo de sexo masculino se hallaron algunos fragmentos de cerámica local. Aparte de dichos fragmentos y algunos huesos de cuy, no había ofrenda alguna de mayor significado.

\section{EL TRATAMIENTO DE LOS MUERTOS}

La información presentada en la sección anterior, y resumida en el cuadro 1, hace ver la existencia de 4 formas de enterramientos practicados en el valle de Acarí durante las fases iniciales del periodo Intermedio Temprano. No obstante que la muestra sigue siendo pequeña y un número significativo de las tumbas están disturbadas, es posible observar la recurrencia de determinados patrones, así como otros aspectos que hasta hace poco eran desconocidos.

Cuadro 1 - Relación de las tumbas considerando varios aspectos de los entierros

\begin{tabular}{|c|c|c|c|c|c|c|}
\hline Tumba & Tipo & Edad & Sexo & Posición & Orientac. & Ofrenda \\
\hline T1- Huarato & con techo & 20- 25 años & $M \neq$ & sentado & norte & cuenco \\
\hline T2- Huarato & con techo & 20-25 años & $\mathrm{F}$ & sentada & norte & mate \\
\hline T3- Huarato & con techo & 35-49 años & $\mathrm{F}$ & sentada & norte & ninguno \\
\hline T4- Huarato & con techo & 5- 9 años & $i ?$ & Envuelto & $i ?$ & ninguno \\
\hline T5- Huarato & con techo & >50 años & $M \neq$ & sentado & norte & mate \\
\hline T6- Huarato & con techo & recién nacido & $i ?$ & Envuelto & $i ?$ & Cesto y yuca \\
\hline T7- Huarato & urna & recién nacido & i? & Envuelto & i? & almoadilla \\
\hline T1- Amato & urna & 3- 9 meses & $i ?$ & Envuelto & $i ?$ & Spondylus \\
\hline T2- Amato & urna & 1- 2 años & $i ?$ & Envuelto & $i ?$ & ninguno \\
\hline T3- Amato & urna & 20- 34 años & $\mathrm{F}$ & sentada & norte & ninguno \\
\hline T4- Amato & urna & recién nacido & $i ?$ & Envuelto & i? & cuy y mate \\
\hline T5- Amato & hoyo & $>60$ años & $M \neq$ & sentado & norte & mate, maní ${ }^{*}$ \\
\hline T1- MGA & hoyo & 35- 49 años & $\mathrm{F}$ & $i ?$ & $i ?+$ & ninguno \\
\hline T2- MGA & urna & 1- $1 \frac{1}{2} 2$ años & $i ?$ & envuelto & $i ?+$ & ninguno \\
\hline T3-MGA & urna & recién nacido & $i ?$ & Envuelto & $i ?+$ & cantimplora \\
\hline T4-MGA & urna & 5-10 años & i? & Sentado & $i ?+$ & ninguno \\
\hline T5- MGA & hoyo & 35- 49 años & $\mathrm{F}$ & sentada & $i ?+$ & batán \\
\hline T6- MGA & urna & 6- 9 meses & $i ?$ & Envuelto & $i ?+$ & ninguno \\
\hline T7- MGA & hoyo & 20-34 años & $\mathrm{F}$ & sentada & norte & ninguno \\
\hline T1- TV & múltiple & 35- 49 años & $\mathrm{F}$ & sentada & norte + & pata de camélido \\
\hline T2- TV & múltiple & 35- 49 años & $M \neq$ & disturbado & i? & ninguno \\
\hline T3- TV & múltiple & >20 años & $M$ & disturbado & $i ?$ & ninguno \\
\hline
\end{tabular}

Nota: $\mathrm{MGA}=$ Monte Grande Alto; TV = Tambo Viejo; + indica entierro disturbado; $>=$ mayor que; $\neq=$ con turbante; $y^{*}=$ entierro que incluye las ofrendas de los camélidos, los Spondylus, además de los individuos decapitados. 
Una primera observación que se extrae de estos datos es que la construcción de las estructuras no necesariamente demandó mayor esfuerzo, excepto para la estructura de Tambo Viejo. Una mayoría son hoyos simples. Una segunda observación sobresaliente es, con la única y rara excepción de la estructura con entierros múltiples de Tambo Viejo, el hecho que los entierros contienen un solo individuo. Una tercera observación es el hecho que no obstante las variaciones aquí anotadas, dichas diferencias no tienen ninguna conexión con la edad y el sexo. Es decir que es difícil argumentar si las mejores estructuras fueron reservadas, por decir, para los individuos de sexo masculino. Una excepción parece ser las urnas que generalmente están asociadas con infantes/recién nacidos y jóvenes, pero existe por lo menos un caso donde el individuo es un adulto.

Con la excepción de los infantes y recién nacidos, donde fue imposible determinar la posición y orientación del cuerpo, se observa que todos los entierros intactos, hasta hoy excavados en los sitios del periodo Intermedio Temprano de Acarí, mantienen una posición sentada y una orientación hacia el norte. Aunque será difícil conocer el significado original de esta orientación, se puede entretener la idea que esta tal vez tiene alguna conexión con las montañas y el agua. En efecto, el mismo río Acarí, cuyas aguas irrigan el valle, desciende de dicha dirección. Por cuanto las excavaciones vienen revelando que estos pueblos dependieron del cultivo de una variedad de plantas, queda abierta la posibilidad que el agua, y sobre todo las montañas, fueron veneradas por estas poblaciones.

Otro aspecto digno de discutir es con respecto a las ofrendas. En base a los entierros intactos hasta hoy excavados, se vislumbra un escenario que permite sostener que las ofrendas no fueron un aspecto recurrente en todas las tumbas. Efectivamente, un buen número de entierros carecen de ofrendas. Además, las pocas ofrendas encontradas en algunas tumbas no dejan de ser modestas. De todas estas, la cerámica es el artefacto menos recurrente; por ejemplo, sólo una tumba proveniente de Huarato tenía una ofrenda de cerámica no decorada. Como se podrá observar en el cuadro 1, un buen número de entierros simplemente no posee ofrendas. Sin embargo cuando esto ocurre, estas son variadas.

No obstante el pillaje y la destrucción, la conservación de las tumbas es excepcional, lo que permite observar aspectos normalmente no presentes en otras circunstancias, por ejemplo el tratamientodado al cabello de los individuos adultos. Por un lado, el cabello de las mujeres fue arreglado en varias pequeñas trenzas (ver fig. 3), aunque en el caso de un entierro excavado en Huarato se notó el cabello estaba suelto. Cuando existen, las trenzas son relativamente cortas y no superan los $20 \mathrm{~cm}$ de largo. Muchos entierros profanados por los huaqueros en Monte Grande Alto llevan varias trenzas. Esto sugiere que entre las mujeres era una costumbre llevar las pequeñas trenzas.

Por otro lado, el cabello de los varones, por lo menos en cuatro casos, fue sostenido a la altura del frontal y luego sujetado con un turbante. Para su efecto, se dio al turbante varias vueltas, para finalmente crear una especie de un moño a la altura del frontal. Dos entierros excavados en Huarato llevaban turbantes de color rojo (fig. 11), mientras que uno de los individuos excavado en Tambo Viejo también poseía un turbante negro. La tumba recientemente excavada en Amato (T5-Amato) no llevaba el turbante, pero tenía arreglado el cabello en varias pequeñas trenzas que al final estaban unidas a la altura del frontal. Todo esto indica que los individuos de sexo masculino parecen haber tenido una cabellera también larga. En 1989 se pudo observar en Monte Grande Alto un individuo de sexo masculino que efectivamente tenía la cabellera

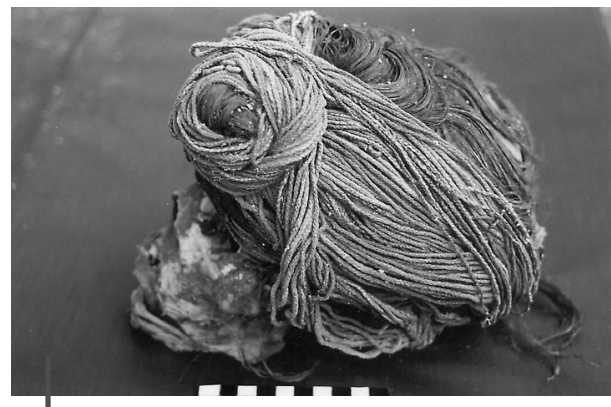

Figura 11- Cráneo con turbante proveniente de Huarato (Tumba 1) 
larga y que tal vez estaba sujetada por un turbante. En este sitio hay turbantes fragmentados, lo que deja abierta la posibilidad que el uso del turbante entre la población masculina de este valle fue relativamente común. En la medida del avance de las investigaciones, será posible determinar a qué edad se inició a llevar el turbante.

Otro aspecto digno de resaltar es la ofrenda encontrada en asociación al entierro de sexo femenino de Tambo Viejo. A un lado de dicho entierro se halló una pata trasera de camélido (Valdez, 2005a). Inicialmente, Miller \& Burger (1995; Burger, 1992: 167) sostuvieron que la ausencia de los huesos de la pata y la cabeza de camélidos en un sitio arqueológico se debía al consumo del charki. Sin embargo, Browman (1989), Kroeber (1998: 80) y este autor (Valdez, 2000b: 570) ya habían notado la presencia de las patas de camélidos como ofrenda de entierros. En base a dicha información, sostuve que no había una asociación directa entre la ausencia de las patas de camélidos de un sitio y el aparente consumo del charki (Valdez, 2000b). La evidencia de Tambo Viejo es otra instancia que demuestra el uso de las patas de camélidos como ofrenda de los muertos, corroborando de este modo mi planteamiento anterior.

En asociación a algunos entierros profanados de Monte Grande Alto y Amato se llegó a recuperar varios ejemplares de cuentas hechas de conchas marinas (fig. 12). Muchas de estas cuentas, que presentan un pequeño orificio en su parte media, están hechas de la valva del Choromytilus chorus, un bivalvo marino de color azulado. Algunas de dichas cuentas fueron todavía halladas con sus respectivos hilos. Desafortunadamente, todavía no se ha excavado un solo entierro que poseía un collar de conchas o en su efecto que tenía varias ofrendas. Una excepción viene a ser el collar de T5 de Amato (Valdez, 2006).

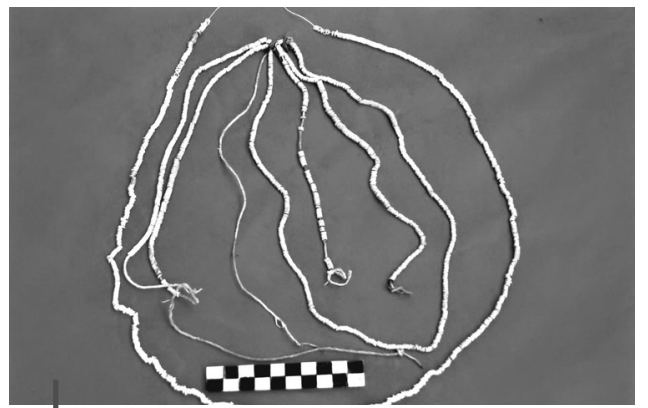

Figura 12 - Cuentas de conchas encontradas cerca de entierros profanados en Monte Grande Alto
Finalmente, otro aspecto que ya merece nuestra atención es el perfil de vida de la población de Acarí. No obstante que la muestra es pequeña, es importante empezar a visualizar este aspecto para así en un cercano futuro poder comparar con datos similares obtenidos para la población Nasca. De la información disponible, parece que había una alta mortalidad durante los primeros años de vida, tal como exponen los resultados presentados en el cuadro 2. Es importante recordar que la mayoría de los individuos incluidos en este grupo son infantes y recién nacidos. La muestra analizada no incluye ejemplar alguno perteneciente a individuos cuyas edades oscilan entre los 15 y 19 años, lo que por ahora sugiere que a esta edad tal vez había menor mortalidad. Posteriormente, entre la población adulta, el número de muertos mantiene cierta uniformidad, para luego decaer entre los adultos mayores de 50 años. Esto obedece generalmente al hecho que pocos individuos debieron haber llegado hasta esta edad, aunque sorprende que no obstante el tamaño pequeño de la muestra dos adultos de sexo masculino sobrepasaron los 50 años de edad.

\section{NASCA Y HUARATO: ¿TRADICIONES CULTURALES DIFERENTES?}

Carmichael (1988; 1995), Isla (2001), Reindel \& Isla (2001) y Orefici \& Drusini (2003) han efectuado diversos estudios acerca de las formas de enterramientos Nasca. Carmichael (1988) en particular ha logrado distinguir varias formas de enterramiento. De acuerdo a dicho análisis, una mayoría de individuos (78\%) de todas las edades y ambos sexos, fueron a menudo enterrados en hoyos de más o menos de un metro de profundidad (Carmichael, 1988: 186). Dichas construcciones, sin pared alguna, algunas veces estaban dotadas de un techo y otras veces no. Cuando ocurren, los techos son de cañas, palos, troncos y barro (Carmichael, 1988: 187). 


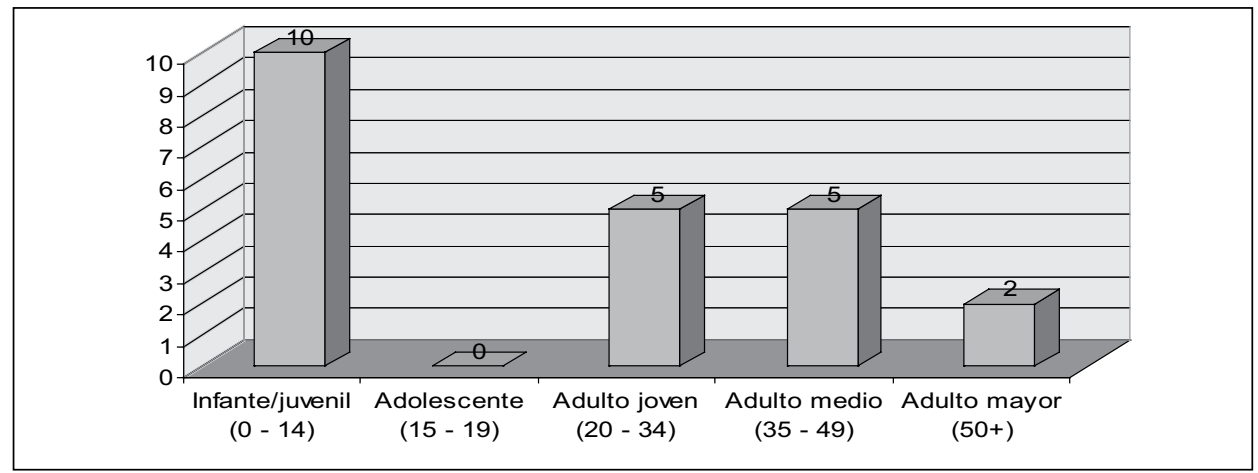

Cuadro 2 - Perfil de la edad al momento de la muerte de los individuos analizados

El valor encima de cada barra representa el número de individuos estudiados.

Entretanto, de acuerdo a Carmichael (1988: 194), la mayoría de los infantes menores de 7 años fueron enterrados en ollas. Carmichael (1988: 196) también anota que algunos entierros Nasca presentan señales (15\%), las mismas que consisten de una caña, un palo, un tronco, o un adobe. Carmichael no menciona la presencia de cantos rodados como señales de tumbas.

Entretanto, una práctica común Nasca para enterrar sus muertos fue la construcción de las llamadas «barbacoas» (Isla, 2001: 214-216), las mismas que son entierros profundos dotados de techos construidos con palos de huarango que miden por lo menos 2,80 y 3,20 metros de largo. Orefici \& Drusini (2003: 117) sostienen que las barbacoas fueron comunes durante las primeras fases del desarrollo Nasca. En este caso, los autores mencionan que «las paredes de las barbacoas estaban reforzadas con cantos rodados o adobes, [mientras] que para la cobertura se utilizaron palos de algarrobo». (Orefici \& Drusini 2003: 117) Hasta la fecha no se conoce un sólo ejemplo de barbacoa en Acarí.

Por otro lado, Carmichael (1988: 180, 182; 1995: 166) y Orefici \& Drusini (2003: 117) mencionan que el 73 ó 79 \% de los entierros Nasca fueron colocados en una posición sentada, con las rodillas flexionadas hacia el pecho y las manos sujetadas hacia el pecho. Se conoce además que la mayoría de los entierros (47\%) Nasca mantenían una orientación hacia el sur (Carmichael, 1988: 184), aunque Orefici \& Drusini (2003: 117) sostienen que un buen número de las tumbas de Cahuachi y Pueblo Viejo estaban orientas hacia el oeste. Y, de acuerdo a Carmichael (1988: 496), ningún entierro Nasca presenta turbantes, aunque sí anota que existen algunos ejemplares de turbantes al parecer colocados como ofrendas de individuos adultos. Cabe agregar que en ninguno de los casos estudiados por Carmichael, los turbantes estaban en la posición en la que fueron hallados en Huarato y Tambo Viejo. Una excepción parece ser uno reportado por Reindel \& Isla (2001: 253). Sin embargo, dicho hallazgo es distinto a los provenientes de Acarí. En consecuencia, existe la posibilidad que el uso de los turbantes entre la población masculina de Acarí tal vez fue una forma de distinguirse de sus vecinos y una forma de identificarse como poblador del valle de Acarí.

A su vez, todo entierro Nasca estaba dotado de ofrendas (Orefici \& Drusini, 2003: 118). Entre estas la fina cerámica Nasca constituye uno de los elementos más recurrentes (Carmichael, 1988: 306). El entierro considerado «más pobre» tenía por lo menos una vasija. Tal como se ha observado, ninguno de los entierros hasta hoy excavados en Acarí tenían como parte del ajuar funerario objeto Nasca y menos la fina cerámica Nasca. Esta observación es de mucho significado y denota que los entierros hasta hoy excavados en Acarí son prácticas locales. Previamente (Valdez, 1998: 162, 183), sugerí que determinados individuos de Acarí tal vez utilizaron determinados artefactos Nasca, como la fina cerámica, como objetos de lujo para 
elevar su prestigio personal y status social. Dichos individuos, se anticipó, una vez muertos también estarían asociados a tales objetos, mientras que el resto de la población obviamente carecería de dicho bienes. Definitivamente hay objetos Nasca en Acarí (Valdez, 2000a: 170), pero el contexto original de dichos artefactos sigue incierto.

Por ahora, la ausencia de artefactos Nasca como parte del ajuar mortuorio, sugiere que los entierros hasta hoy excavados probablemente son anteriores al tiempo en que los habitantes de Acarí entraron en contacto con sus vecinos del norte. Una posibilidad alterna es que los entierros hasta hoy excavados pertenecen a un sector de la población que nunca llegó a adquirir prestigio alguno. Sin embargo, el hecho que el entierro T5 de Amato estaba asociado a muchos individuos decapitados, sugiere que entre los entierros excavados existen individuos con prestigio.

Aquí es preciso considerar algunos fechados obtenidos para los contextos de Acarí. Una muestra de carbón recuperada de las inmediaciones de las tumbas con techo de Huarato arrojó un fechado de 40 a.C.; otra muestra de carbón hallada junto a T3 de Amato arrojó un fechado de 245 d.C. En ninguno de estos contextos había cerámica Nasca. Tal como ya se anotó, existe un fechado de 20 d.C. para el individuo adulto masculino (T5) de Amato. Excepto la segunda fecha, las otras son bastante tempranas y parecen confirmar que ambas pertenecen a una fase anterior a la llegada de la cerámica Nasca al valle de Acarí. Carbón recuperado en Huarato de contextos con cerámica Nasca arrojó un fechado de 250 d.C. Por lo tanto, estos fechados nos permite visualizar, aunque tentativamente, la fecha de la llegada de los artefactos Nasca hacia este valle y el tiempo aproximado del contacto iniciado entre las poblaciones Nasca y sus vecinos de Acarí. Si este escenario es confirmado por estudios posteriores, no habrá duda que los entierros aquí discutidos son definitivamente anteriores a la interacción con Nasca.

De este modo, mientras existen algunas similitudes generales entre las tumbas Huarato de Acarí y Nasca, las diferencias son notables en varios aspectos. Por ejemplo, los entierros Huarato no presentan un techo pesado como los entierros Nasca. Para Huarato tampoco se conoce de señales de caña, adobes o troncos. En muchos casos, los entierros provenientes del sitio de Huarato son modestos y definitivamente para la construcción de las tumbas, por ejemplo, se gastó poco esfuerzo y recursos. Del mismo modo, sólo en un caso se encontró una ofrenda de cerámica (fig. 13), y este no era la fina cerámica Nasca. Este hecho refuerza las sugerencias hechas anteriormente en base a la evaluación de la cerámica que precisamente denotó diferencias substanciales que ya dejaban evidente la existencia de una tradición local en Acarí (Carmichael, 1992; Valdez, 1998; 2000a).

Entretanto, la posición y orientación de los cuerpos es también de igual interés. Aunque en ambos casos se observa la posición sentada con las rodillas flexionadas hacia el pecho, cabe destacar que hay diferencias en la forma como los brazos fueron dispuestos. Los de Nasca mantienen sus brazos pegados o cerca al pecho (o la cara [Orefici \& Drusini, 2003]), mientras los de Acarí lo llevan por debajo de las extremidades inferiores (cerca a los genitales) o cerca de

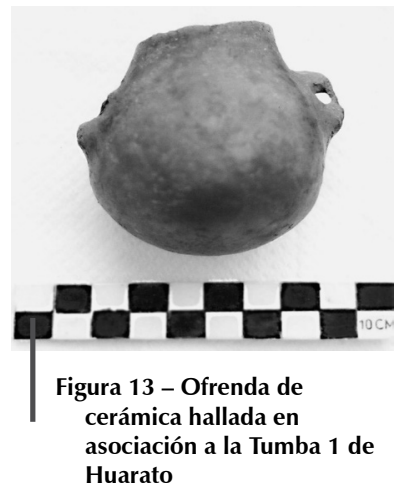
los pies. Del mismo modo, los entierros de Huarato (excepto uno), mantienen una orientación hacia el norte (dirección de la parte alta del valle), mientras que una mayoría de los entierros Nasca están orientados hacia el sur. Estas dos diferencias bien podrían estar reflejando diferencias de orden ideológico y religioso. La población del valle Acarí tal vez dio mayor importancia al río de Acarí y a las montañas por ser estas las proveedoras del agua; por su lado, para la población Nasca el concepto tal vez no fue el mismo, o la preocupación no fue expresada de la misma forma. De ser así, parece que existían diferencias conceptuales entre estas dos tradiciones culturales.

Finalmente, los estudios de las formas mortuorias Nasca hasta la fecha no han ubicado una sola estructura similar a 
aquella recientemente descubierta en Tambo Viejo. Si bien el hallazgo en mención no tiene la complejidad de las estructuras mortuorias Nasca (ver Reindel \& Isla, 2001: 262), la estructura descubierta en Tambo Viejo es del todo diferente de cualquiera forma mortuoria Nasca; como tal, este también deja abierta la posibilidad que esta estructura sea una manifestación local.

Merece insistir que las formas de enterramiento son instituciones idiosincrásicas y muy conservadoras dentro de toda sociedad. Al igual que la vestimenta, la forma como los miembros de una sociedad depositan a sus muertos está sancionada colectivamente por la sociedad y como tal se mantiene estable, aún en situaciones de conflicto o desastre. Como miembro que fue de una sociedad, el fallecido no se aleja de ella con la muerte. Más bien, se convierte en un miembro que preserva las costumbres y tradiciones, tradición que el resto de la comunidad se encarga de mantener. Por esta misma particularidad, aunque se conoce que una tumba puede ser manipulada, el estudio de estructuras funerarias y su contenido es de vital importancia para distinguir tradiciones culturales.

Cieza de León (1973 [1553]: 164), ya había notado las diferencias que tenían los diferentes pueblos de los Andes centrales para depositabar a sus muertos. Posteriores análisis precisamente han revelado que cada cultura tenía sus formas particulares de depositar a sus muertos (ver Dillehay, 1995; Valdez et al., 2002). De estos se sabe que algunos acostumbraron depositar ricos ajuares funerarios que incluían sacrificios humanos y de animales, mientras que otros fueron más modestos. Otros buscaron mantener contacto con los muertos y para lo cual establecieron estructuras funerarias accesibles. Otros pueblos no compartieron la misma filosofía y optaron por sellar a sus muertos por completo. Algunos pueblos establecieron cementerios específicos, mientras algunos optaron por guardar o enterrar a sus muertos en el mismo lugar de residencia, tal vez para no distanciarse de sus seres queridos. Todas estas diferencias son elementos que los especialistas podemos observar, pero hay otros aspectos que no han dejando algo tangible para ser vistos y analizados. En la ausencia de tales aspectos, el material cultural disponible constituye la única fuente para comprender las formas de enterramientos del pasado y desde luego la concepción de una sociedad del pasado con respecto a sus muertos. Se debe recordar, al mismo tiempo que tales actos rituales y las formas de inhumación varían entre todas las culturas (Van Gennep, 1960: 146). Dichas variaciones también se reflejan arqueológicamente de diversas maneras; tal es el caso de la postura de los muertos o el tipo de ofrendas ahí depositadas. Por lo tanto, la observación cuidadosa de tales diferencias es de mucha importancia, especialmente cuando se estudian diferentes tradiciones culturales que podrían ser distintas.

\section{DISCUSIÓN Y COMENTARIO FINAL}

En este trabajo se describen los elementos más resaltantes de los patrones de enterramientos observados en los sitios del periodo Intermedio Temprano del valle de Acarí. Como se ha notado, comparado a Nasca, existen varios aspectos que son similares, así como diferencias significativas. Dichas diferencias, además de la ausencia de la policroma cerámica Nasca que para los entierros Nasca es un elemento diagnóstico, deja evidente que durante el auge del centro ceremonial de Cahuachi en el valle de Nasca (Silverman, 1993; Silverman \& Proulx, 2002), el valle de Acarí fue ocupado por una tradición cultural distinta a Nasca. Dicha tradición cultural, (Valdez, 1998; 2000a), se diferenció de Nasca no sólo en la forma de depositar a sus muertos, sino también en la forma de construir sus asentamientos y la forma de manufacturar su propia cerámica (Valdez \& Ríos, 2005). Estos son sólo algunos elementos que por ahora conocemos. En la medida en que avancen los estudios, es de anticipar que otras variables serán descubiertas. De suceder eso, se podrá no sólo comprender mejor el carácter del desarrollo de los pueblos de la costa sur, sino de la dinámica cultural del valle de Acarí.

Tal como ocurre en la actualidad entre cualquiera población, la muerte entre los antiguos habitantes de Acarí posiblemente fue explicada de diversas formas y que como respuesta a dicho evento difícil de aceptar, como es la partida sin retorno de los seres queridos, se 
desarrollaron diversas formas de enterramiento y los respectivos actos rituales. Muchos de estos procedimientos no son posibles de observar, pero existen varios indicios que de alguna u otra forma nos permiten acercarnos a percibir partes de tales procedimientos. La más sobresaliente es la forma de depositar a los muertos bajo tierra y siempre aislados. Este hecho tal vez reflejó la conexión de la población con la pachamama, a donde «al final del camino» uno tenía que ingresar. Para tal ingreso, por alguna razón aún poco clara por el momento, algunos individuos fueron proveídos de botellas de mate o pequeñas cantimploras de cerámica posiblemente para «llevar» alguna bebida. Como ofrenda adicional también aparecen los depósitos de cuy y raíces de yuca. Otros individuos llevaron también algunos objetos de lujo, como fueron los collares hechas de cuentas de las valvas del Choromytilus chorus. A parte de tales objetos, el ajuar funerario no dejó de ser modesto.

A partir de los hallazgos efectuados en Huarato y Amato también se hace patente que el fuego fue parte importante de los rituales hacia los muertos. La presencia de tierra quemada y ceniza precisamente encima de las tumbas y encima del primer sello de arcilla, sugiere que antes de sellar por completo la tumba, se tenía que prender fuego, tal vez con la finalidad de purificar el espíritu y facilitar el rápido y fácil tránsito al más allá. Es de particular interés anotar que evidencias de fuego sólo aparecen asociados a entierros de individuos adultos.

Finalmente, los muertos en Acarí no fueron del todo separados de la población del que una vez formaron parte. En lugar de establecer un cementerio fuera de los lugares residenciales, los muertos fueron depositados al interior del mismo complejo y al interior de estructuras residenciales o de actividades. Efectivamente, muchos entierros aparecen a lo largo de los muros y siempre al interior de estructuras. La cubierta o techo de algunos hoyos que contenían a los muertos no estaba lejos del piso de la estructura y da la impresión que había cierta forma de convivencia entre los muertos y la población.

Cuando la población del valle de Acarí entró en contacto con Nasca, todo parece indicar que la forma de tratar a los muertos sufrió algunas modificaciones. Aunque no se ha excavado un solo caso para confirmar esta posibilidad, existen reportes de algunos vecinos del sitio de Huarato acerca de la presencia de objetos Nasca hallados en asociación a entierros. Tales objetos Nasca incluyen la fina cerámica y algunos objetos de oro (fig. 14). Por lo tanto, parece más probable que los entierros hasta hoy excavados en Acarí anteceden al tiempo de contacto entre las poblaciones de Acarí y sus vecinos de Nasca. Efectivamente, los fechados de carbón hasta hoy obtenidos confirman la temprana ubicación temporal de los entierros hasta hoy excavados en Acarí, a la vez que datos similares vienen indicando que las primeras muestras de la alfarería Nasca hicieron su ingreso a sitios como Huarato alrededor del año 250 d.C.

En síntesis, la evidencia mortuoria de los sitios de Acarí presenta características interesantes y rasgos únicos que permiten diferenciarlos de sus vecinos Nasca. En la medida que nuevos descubrimientos salgan a la luz, es muy probable

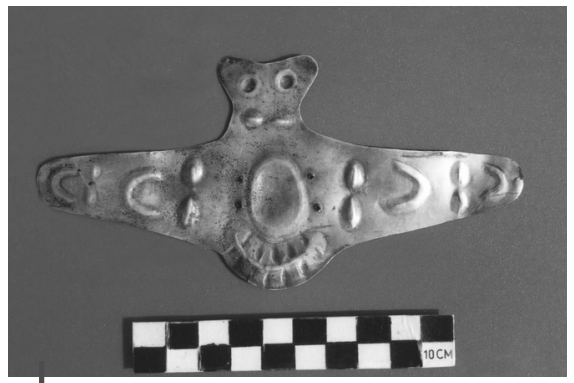
que se aprenderá más acerca de las costumbres mortuorias de esta sociedad que, como se anotó al inicio, fue desafortunadamente ignorada por los especialistas. Este análisis, además de otros estudios acerca de la dieta, actividades, manufactura, entre otros, esclarecerá aspectos importantes de la población denominada Huarato, permitiendo a la vez comprender mejor el desarrollo de las poblaciones de la costa sur peruana durante el periodo del auge de la cultura Nasca.

Figura 14 - Diadema de oro elaborado en el estilo Nasca temprano y encontrado por un vecino del sitio de Huarato. 


\section{Agradecimientos}

Mi reconocimiento para las autoridades del Instituto Nacional de Cultura por el permiso cedido para llevar adelante los trabajos de excavación en los sitios de Huarato y Amato. Mis gracias se hacen extensivo para Nilton Ríos, Milagros Paúcar, María Ysela Leyva, Kristen Baker, Lisa Weingarten, Ida M. Andersen, Craig Smith, Sylvere Valentin, Virginia Cannon, Sarah Kamp, Laura Sánchez, Marco de la Cadena, Carlos A. Morán, Roger V. Segura, Roger A. Morales, Samuel Pedroza, Manuel H. Chalco, Erika E. Segura, Amy Raes, Emilie Gustafsson, Angus Danielson, Erin Graham, Natasha Merritt, María Quiroga, Heidi Morrison, Maribel Quiroga, Lauren Norman, Karen Smith, Trisha Brown, Erin Willows, Olivia Chmielewski, Eden Dilley, Amanda Aland, Regina McGowan, Martin Cantalicio, Sheryl Spigelski, Kim Statham, Heather Battles, Luseadra McKerracher, Annette Baus, Jennifer Storey, Karen Bernofsky, Elanor Dilley, Jamie L. Rasenberg, Patrick Kuse, Annalisa Christie, Matthew Taylor, Karin Perro, Rhonda Coolidge, Lisa Weingarten y Rosanna M. Kaser por su valiosa participación en los trabajos de excavación y de gabinete durante las dos temporadas. Agradezco también a Waren A. Smith por la preparación de la figura 1. La traducción del resumen en Francés fue gentilmente preparado por la Dra. April Nowel. Mi agradecimiento también para Angel Iglesias y esposa Rosa Mazuelo, por la hospitalidad brindada durante nuestra estadía en Acarí. Del mismo modo, mis gracias para los vecinos de los sitios arqueológicos de Huarato y Amato, así como a las autoridades y vecinos de Acarí por mostrar interés en la investigación arqueológica. Por último mis agradecimientos para los evaluadores de IFEA, Bruce Owen y Johny Isla, por los comentarios y sugerencias a una versión inicial de este trabajo. Todo error y mala interpretación es de total responsabilidad de este autor.

\section{Referencias citadas}

BROWMAN, D. L., 1989 - Origins and development of Andean pastoralism: an overview of the past 6000 years. In: The Walking Larder: Patterns of Domestication, Pastoralism, and Predation (J. Clutton-Brock, ed.): 256-268; London: Unwin Hyman.

BURGER, R. L., 1992 - Chavín and the Origins of Andean Civilization, 248 p.; London: Thames and Hudson.

CARMICHAEL, P. H., 1988 - Nasca Mortuary Customs: Death and Ancient Society on the South Coast of Peru, 587 p.; Calgary: University of Calgary, Ph. D. Dissertation, Department of Archaeology.

CARMICHAEL, P. H., 1992 - Local traditions during the Early Intermediate Period on the South Coast of Peru. Willay, 37-38: 4-6.

CARMICHAEL, P. H., 1995 - Nasca Burial Patterns: social structure and mortuary ideology. In: Tombs for the Living: Andean Mortuary Practices (T. D. Dillehay, ed.): 161-187; Washington, DC: Dumbarton Oaks.

CARMICHAEL, P.H., 1998 - Nasca ceramics: production and social organization. In: Andean Ceramics: Technology, Organization, and Approaches (I. Shimada, ed.): 213-231; Philadelphia: University of Pensylvania, Museum of Archaeology and Anthropology.

CARNEIRO, R., 1970 - A theory of the origin of the state. Science, 169: 733-738.

CARPIO, A., 1942 - Datos sobre la arqueología de los valles de Acarí y Yuaca. In: XXVII Congreso Internacional de Americanistas, Actas y Trabajos Científicos de la Segunda Sesión, Vol. I: 435-529; Lima.

CIEZA DE LEÓN, P., 1973 [1553] - La crónica del Perú, 262 p.; Lima: Ediciones Peisa, Biblioteca Peruana.

DILLEHAY, T. D. (ed.), 1995 - Tombs for the Living: Andean Mortuary Practices, 245 p.; Washington, D.C.: Dumbarton Oaks.

FLANNERY, K. V., 1972 - The cultural evolution of civilization. Annual Review of Ecology and Systematics, 3: 339-426. 
Los vecinos de Nasca: entierros de la tradición Huarato del valle de Acarí, Perú

FRIED, M. H., 1968 - The Evolution of Political Society, 270 p.; New York: Random House.

ISLA, J., 2001 - Una tumba Nasca en Puente Gentil, valle de Santa Cruz, Perú. Beitrage Zur Allgemeinen Und Vergleichenden Archaologie, 21: 207-239.

KENT, J. D. \& KOWTA, M., 1994 - The cementery at Tambo Viejo, Acari Valley, Peru. Andean Past, 4: 109-140.

KROEBER, A. L., 1998 - Excavations. In: The Archaeology and Pottery of Nazca, Peru (P. H. Carmichael, ed.): 39-83; Walnut Creek: Altamira Press.

KROEBER, A. L. \& STRONG, W. D., 1924 - The Uhle collections from Ica. Publications in American Archaeology and Ethnology, 21: 95-133; Berkeley: University of California.

LANNING, E. P., 1967 - Peru before the Incas, 225 p.; New Jersey: Prentice-Hall, Inc., Englewood Cliffs.

MASSEY, S. A., 1986 - Sociopolitical Change in the Upper Ica Valley, B.C. 400 to 400 A.D.: Regional States on the South Coast of Peru, 420 p.; Los Angeles, California: University of California, Ph. D. Dissertation, Department of Anthropology.

MENZEL, D. \& RIDDELL, F. A., 1986 - Archaeological Investigations at Tambo Viejo, Acari Valley, Peru 1954, 123 p.; Sacramento: California Institute for Peruvian Studies.

MENZEL, D., J. H. ROWE \& DAWSON, L. E., 1964 - The Paracas Pottery from Ica: A Study in Style and Time, 351 p.; Berkeley \& Los Angeles: University of California Press.

MILLER, G. R. \& BURGER, R. L., 1995 - Our father the cayman, our dinner the llama: animal utilization at Chavín de Huantár, Perú. American Antiquity, 60: 421-458.

MOSELEY, M. E., 1992 - The Incas and their Ancestors: the Archaeology of Peru, 272 p.; London: Thames \& Hudson.

OREFICI, G. \& DRUSINI, A., 2003 - Nasca: hipótesis y evidencias de su desarrollo cultural, 267 p.; Brescia: Centro Italiano Studi e Ricerche Archeologiche Precolombiane.

PROULX, D. A., 1968 - Local Differences and Time Differences in Nasca Pottery, 180 p.; Berkeley \& Los Angeles: University of California Publications in Anthropology 5.

PROULX, D. A., 1971 - Headhunting in ancient Peru. Archaeology, 24: 16-21.

PROULX, D. A., 2001 - Ritual uses of trophy heads in ancient Nasca society. In: Ritual Sacrifice in Ancient Peru (E. P. Benson \& A. G. Cook, eds.): 119-136, Austin: University of Texas Press.

REINDEL, M. \& ISLA, J., 2001 - Los Molinos und La Muña. Zwei Siedlungszentren der NascaKultur in Palpa, Sudperu. Beitrage Zur Allgemeinen Und Vergleichenden Archaologie, 21: 241-319.

RIDDELL, F. A. \& VALDEZ, L. M., 1988 - Prospecciones Arqueológicas en el Valle de Acarí, costa sur del Perú, 221 p.; Sacramento: California Institute for Peruvian Studies.

ROWE, J. H., 1954 - Max Uhle, 1856-1944: A Memoir of the Father of Peruvian Archaeology; Berkeley \& Los Angeles. University of California Publications in American Archaeology and Ethnology 46.

ROWE, J. H., 1956 - Archaeological explorations in southern Peru. American Antiquity, 22: 135-151.

ROWE, J. H., 1963 - Urban settlements in ancient Peru. Nawpa Pacha, 1: 1-27.

SAWYER, A. R., 1961 - Paracas and Nazca iconography. In: Essays in Pre-Columbian Art and Archaeology (S. Lothrop, ed.): 269-298; Cambridge: Harvard University Press.

SCHREIBER, K. J., 1998 - Afterword: Nasca Research since 1926. In: The Archaeology and Pottery of Nazca, Peru: Alfred L. Kroeber's 1926 Expedition (P. H. Carmichael, ed.): 26270; Walnut Creek: Altamira Press.

SERVICE, E. R., 1962 - Primitive Social Organization: an evolutionary perspective, 211 p.; New York: Random House.

SILVERMAN, H., 1988 - Cahuachi: non-Urban cultural complexity on the South Coast of Peru. Journal of Field Archaeology, 15: 403-430. 
SILVERMAN, H., 1993 - Cahuachi in the Ancient Nasca World, 371 p.; lowa City: University of lowa Press.

SILVERMAN, H. \& PROULX, D., 2002 - The Nasca, 339 p.; Malden: Blackwell Publishers.

STRONG, W. D., 1957 - Paracas, Nazca, and Tiahuanacoid cultural relationships in South Coastal Peru, 48 p.; Salt lake City: The Society for american archaeology. Memoirs of the Society for American Archaeology 13, Vol. 22 (4), part 2.

VALDEZ, L. M., 1994 - Investigaciones arqueológicas en Gentilar, Acarí. Boletín de Lima, 91-96: 351-361.

VALDEZ, L. M., 1996 - Los depósitos Inka de Tambo Viejo, Acarí. Tawantinsuyo, 2: 37-43.

VALDEZ, L. M., 1998 - The Nasca and the Valley of Acarí: Cultural Interaction on the Peruvian South Coast During the First Four Centuries A.D, 248 p.; Calgary: University of Calgary, Ph. D. Dissertation, Department of Archaeology.

VALDEZ, L. M, 2000a - La tradición cultural de Huarato de Acarí y sus relaciones con Nasca. Arqueología y Sociedad, 13: 159-171.

VALDEZ, L. M., 2000b - On ch'arki consumption in the ancient Central Andes: a cautionary note. American Antiquity, 65: 567-572.

VALDEZ, L. M., 2005a - Early intermediate period mortuary practices in the Acari Valley, Peru. Ponencia presentada al $45^{\text {th }}$ Annual Meeting of the Institute of Andean Studies, University of California, Berkeley. Enero 7 y 8, 2005.

VALDEZ, L. M., 2005b - Patrones funerarios del periodo Intermedio Temprano del valle de Acarí. Corriente Arqueológica, 1: 43-60.

VALDEZ, L. M., 2005c - Resting places in antiquity: the case of the Acari Valley, Peru, during the Early Intermediate Period. Ponencia presentada al $38^{\text {th }}$ Annual Chacmool Conference, University of Calgary, Calgary Noviembre 10 - 13, 2005.

VALDEZ, L. M., 2006 - A bird-bone necklace from Amato, Acari Valley, Peru. Canadian Zooarchaeology, 23: 3-9.

VALDEZ, L. M., BAKER, K. N., RAES, A. \& GUSTAFSSON, E. 2006 - A two thousand year-old mass human sacrifice at Amato, Acari Valley, Peru. Ponencia presentada al $45^{\text {th }}$ Annual Meeting of the Institute of Andean Studies, University of California, Berlkeley, Enero $6-7,2006$.

VALDEZ, L. M., BETTCHER, K. J. \& VALDEZ, J. E., 2002 - New Wari mortuary structures in the Ayacucho Valley, Peru. Journal of Anthropological Research, 58: 389-407.

VALDEZ, L. M. \& RIOS, N., 2005 - El significado social de la cerámica Nasca encontrada en el valle de Acarí. Ponencia presentada al III Seminario de Arqueología UNFV, Lima, Setiembre 2, 2005.

VAN GENNEP, A., 1960 - The Rites of Passage: a Classic Study of Cultural Celebrations, 198 p.; Chicago: University of Chicago Press.

VAUGHN, J. K. \& NEFF, H., 2000 - Moving beyond iconography: neutron analysis of ceramics from Marcaya, Peru, an early Nasca domestic site. Journal of Field Archaeology, 27: 75-90. 